\title{
Long-Lasting Effect of Prolonged Hypoxemia after Birth on the Immediate Ventilatory Response to Changes in Arterial Partial Pressure of Oxygen in Young Lambs ${ }^{1}$
}

\author{
MALGORZATA SLADEK, ROBERT A. PARKER, JENS B. GRǑGAARD, AND \\ HÄKAN W. SUNDELL \\ Departments of Pediatrics and Preventive Medicine, Vanderbilt University School of Medicine, \\ Nashville, Tennessee 37232-2585
}

\begin{abstract}
The effect of prolonged hypoxemia (H) after birth on the evolution of the ventilatory response to changes in arterial partial pressure of $\mathrm{O}_{2}$ was determined in unanesthetized, awake lambs. $H$ was induced for $12 \mathrm{~d}$ after birth in seven lambs through exposure to 0.10 fraction of inspired $\mathrm{O}_{2}\left(\mathrm{FiO}_{2}\right)$. Five control $(\mathrm{C})$ lambs were kept in $0.21 \mathrm{FiO}_{2}$. The ventilatory response (percent increase from baseline) to acute hypoxia was tested with $0.14 \mathrm{FiO}_{2}$ and $0.10 \mathrm{FiO}_{2}$. The tonic activity of the peripheral chemoreceptors was assessed by the transient pure oxygen inhalation test (Dejours' test). The occlusion technique was used to measure the baseline neuromuscular drive of breathing. A markedly decreased early ventilatory response to acute hypoxia persisted in the $H$ lambs for at least 5 wk after termination of $\mathbf{H}$ compared with the $\mathbf{C}$ group. The second phase of the response was significantly lower only at $12 \mathrm{~d}$ (the end of $\mathbf{H}$ ) and was thereafter comparable to that in the $\mathrm{C}$ lambs. The ventilatory response to hyperoxia was significantly lower in the $H$ lambs only at the end of hypoxemia at $12 \mathrm{~d}$ and rapidly normalized after return to normoxia. H did not significantly affect resting neuromuscular drive. These results show that postnatal maturation of the ventilatory response to changes in arterial partial pressure of $\mathrm{O}_{2}$ can be delayed by prolonged postnatal hypoxemia. The effect on the response to hyperoxia is transient, whereas the response to acute hypoxia is affected for an extended time. This study illustrates the importance of an adequate postnatal arterial partial pressure of $\mathrm{O}_{2}$ for the development of the ventilatory response to acute hypoxia. (Pediatr Res 34: 821-828, 1993)
\end{abstract}

\section{Abbreviations}

C, control

CB, carotid body

$\mathrm{H}$, prolonged hypoxemia (experimental group)

$\mathrm{FiO}_{2}$, fraction of inspired oxygen

$\mathrm{PaCO}_{2}$, arterial partial pressure of $\mathrm{CO}_{2}$

$\mathrm{PaO}_{2}$, arterial partial pressure of $\mathrm{O}_{2}$

RR, respiratory rate

$\dot{V}_{\mathbf{l}}$, minute ventilation

$V_{T}$, tidal volume

$P_{0.1}$, airway pressure achieved at $0.1 \mathrm{~s}$ after the onset of inspiration

Received January 19, 1993; accepted August 17, 1993.

Correspondence: Hảkan W. Sundell, M.D. Professor of Pediatrics, Vanderbilt University Medical School, Room U-1212, MCN, Nashville. TN 37232-2585.

Supported by grants from the National Institutes of Health (HD22721 and HL14214).

'Presented in part at the annual meetings of the Society for Pediatric Research and the American Thoracic Society 1990.
The immediate ventilatory response to hypoxia and hyperoxia is principally mediated by the peripheral chemoreceptors located in the CB (1-3). The magnitude of this response is proportional to the strength of $\mathrm{O}_{2}$-sensitive chemoreceptors and is abolished by $C B$ denervation (2-4). The role of $C B$ in the ventilatory regulation in utero, at the time of relative hypoxemia and hypercapnia, still remains unresolved and controversial $(5,6)$. Recent studies have indicated that the peripheral chemoreceptors are responsive to changes in oxygen tension during fetal life (7-9), although the respiratory response to hypoxemia in the fetus is notably different from that after birth, because severe hypoxemia abolishes fetal breathing movements $(10,11)$. The $C B$ response to hypoxic stimuli is overruled in the fetus by a central mechanism $(8,12)$ probably located at the upper lateral pons $(13)$. It has recently been suggested that low $\mathrm{PaO}_{2}$ stimulates a suprapontine center sensitive to hypoxemia that inhibits the medullary respiratory center rather than directly depresses fetal breathing at the medullary level (14). The mechanism of transition from a fetal to an adult response pattern has been a subject of much interest, and some evidence has been presented showing that the resetting is dependent, at least in part, on the increase in $\mathrm{PaO}_{2}$ $(8,15)$. After birth, the chemoreceptors become silent, presumably because of the relative hyperoxia of the extrauterine milieu, and their tonic activity progressively resets to a higher oxygen level $(7,16,17)$. This transition occurs slowly as the result of maturational processes occurring over the first $2 \mathrm{wk}$ after birth (18-21).

Recently, there has been much interest in the study of peripheral chemoreceptor function in infancy because of a possible relationship between hypoxic exposure, $\mathrm{CB}$ malfunction, and the sudden infant death syndrome $(22,23)$. Inadequate respiratory control and failure to respond to acute hypoxemia may initiate a pattern of chronic hypoxemia. Furthermore, alternation in respiratory reflexes was postulated as a possible mechanism in sudden infant death syndrome (24). Contradictory results of the effect of prolonged hypoxemia on the chemoreceptor hypoxic sensitivity in adult cats have been presented. Barnard et al. (25) showed that $28 \mathrm{~d}$ of chronic hypoxemia in cats significantly increased the chemoreceptor response to acute hypoxia, whereas Tatsumi et al. (26) showed in cats that a decreased peripheral chemoreceptor responsiveness to hypoxemia is associated with an attenuated CNS translation of chemoreceptor input. A delayed maturation of the ventilatory response pattern to acute hypoxemia has been observed in newborn rats (27) and kittens (21) after exposure to chronic hypoxemia after birth.

The present study was designed to evaluate the effects of 
prolonged hypoxemia after birth on the evolution of the ventilatory response to acute hypoxia and hyperoxia in term awake and unanesthetized lambs. It was of interest to determine whether prolonged hypoxemia merely delayed the maturational changes or had additional effects on respiratory control.

\section{MATERIALS AND METHODS}

Twelve full-term, vaginally delivered lambs of mixed breed were used in this study. Seven lambs, forming the $\mathrm{H}$ group, were continuously exposed to $0.10 \mathrm{FiO}_{2}$ in a $0.85-\mathrm{m}^{3}$ normobaric chamber for 11 to $14 \mathrm{~d}$ (average $12 \mathrm{~d}$ ) after birth except for 2-3 $\mathrm{h}$ after birth and for 15-min periods 5 times a day for feeding, catheter care, and cleaning of the chamber. The total gas flow introduced into the chamber was $21 \mathrm{~L} / \mathrm{min}$. The oxygen concentration of the mixture of air and nitrogen was monitored continuously with an oxygen analyzer (Ventronics model 5525, Hudson, Ventronics Division, Temecula, CA). $\mathrm{A} \mathrm{CO}_{2}$ absorber was placed in the chamber to avoid an appreciable increase in $\mathrm{CO}_{2}$. The temperature was kept at $21-24^{\circ} \mathrm{C}$. Duration of hypoxemia was based on the study of Hanson et al. (28), who established that, in lambs, the postnatal resetting of CB occurs over a 10-d period. Five lambs were used as a control (C) group and were kept in the chamber with $0.21 \mathrm{FiO}_{2}$ and total gas flow of $21 \mathrm{~L} /$ min for a comparable time period. Thereafter, all lambs were reared with the ewes in room air. Both groups were nursed ad libitum.

$\mathrm{H}$ lambs were studied at an age of $5 \mathrm{~d}$, at the end of hypoxemia on d 11 to 14 (average age $12 \mathrm{~d}$ ), 2 to $4 \mathrm{~d}$ after return to room air (average age $16 \mathrm{~d}$ ), 6 to $7 \mathrm{~d}$ after return to room air (average age $19 \mathrm{~d}$ ), and weekly thereafter until 5 wk after termination of hypoxemia. The $\mathrm{C}$ lambs were studied at comparable time points. The number of animals studied at each time point varied from 4 to 7 in the $\mathrm{H}$ group and from 2 to 5 in the $C$ group. Two lambs died from the experimental manipulation. Some lambs could not be studied when they were older because they were too excitable.

The research protocol was approved by the Vanderbilt University Animal Care Committee.

Instrumentation. On the 3rd postnatal day and using aseptic technique and local anesthesia, the lambs were instrumented with placement of a low tracheostomy and catheters in the cranial tibial artery and lateral saphenous vein, respectively. During the surgical procedures, the $\mathrm{H}$ lambs were breathing $0.10 \mathrm{FiO}_{2}$ to ensure preservation of the effects of prolonged hypoxemia. To allow the lambs to breathe through the upper airway, except when being studied, a 2-inch segment of an endotracheal tube (Portex, Inc., Wilmington, MA) was inserted into the tracheostomy. Antibiotics (gentamicin $4 \mathrm{mg} / \mathrm{kg}$ and carbenicillin 100 $\mathrm{mg} / \mathrm{kg}$ ) were given daily from the time of the instrumentation until the last study. A postoperative $48-\mathrm{h}$ recovery period was allowed before the first study was performed. At the time of each study, the tracheostomy prosthesis was removed and replaced by a downward directed tight-fitting endotracheal tube (Portex 4.58). A tracheostomy tube was used so that ventilation could be measured without leaks during the duration of the acute studies. A pneumotachograph (model $21070 \mathrm{~B}$, Hewlett-Packard, Waltham, MA) was interposed between the endotracheal tube and a Baby Bird respirator (Bird Corp., Palm Springs, CA). During the study, the lambs were breathing spontaneously. The inspiratory flow was $10 \mathrm{~L} / \mathrm{min}$ and the gases were humidified at room temperature. To maintain functional residual capacity, a continuous positive airway pressure of $2-3 \mathrm{~cm}$ of water was applied to compensate for the effect of reduced upper airway tone due to endotracheal intubation.

Recordings. For ventilation measurements, the pneumotachograph flow signal was integrated to yield $\dot{V}_{I}$ or tidal volume $V_{T}$ when needed. The pneumotachograph was connected to a differential pressure transducer (model 270, Hewlett-Packard) and a respiratory integrator (model 8815A, Hewlett-Packard). Statham transducers (model P23ID, Gould-Statham, Oxnard, CA) were used for pressure measurements. All recordings were made with an eight-channel Hewlett-Packard 7758B recording system.

The lambs were monitored during the experimental period with continuous recordings of arterial pressure, heart rate, and serial blood gas analyses (Corning model $158 \mathrm{pH} /$ Blood Gas Analyzer, Ciba Corning Diagnostics Corp., Medfield, MA).

Experimental protocol. The lambs were studied unanesthetized, lightly restrained in a sling (Alice King Chatham, Medical Arts, Los Angeles, CA) while they were awake and quiet (open eyes, regular breathing, and absence of body movement). The lambs were studied only if their rectal temperature was normal $\left(39 \pm 0.5^{\circ} \mathrm{C}\right)$ and if they had no sign of infection. The ambient temperature was maintained at $21-24^{\circ} \mathrm{C}$. Before the onset of the study, the animals were allowed to become familiar with the equipment. At each determined age and within $2 \mathrm{~h}$ of breathing $0.21 \mathrm{FiO}_{2}$, all lambs were exposed to one set of measurements of respiratory output indices and hypoxic and hyperoxic challenges as described below. Each trial was begun when ventilation was judged to be stable, and measurements were always performed in the same order: respiratory output indices, $0.14 \mathrm{FiO}_{2}$ test, hyperoxia test, and $0.10 \mathrm{FiO}_{2}$ test. The lambs were allowed at least 20 min to recover between each test.

Respiratory drive and respiratory timing indices. The occlusion technique, which uses airway pressure at $0.1 \mathrm{~s}$ after the onset of an occluded inspiration as an index of central inspiratory drive, was used during resting conditions while the lambs were breathing $0.21 \mathrm{FiO}_{2}(29)$. To perform these measurements, the respirator was disconnected and a small polyethylene catheter (inner diameter $=0.71 \mathrm{~mm}$ ) was inserted into the endotracheal tube for tracheal pressure recordings. The occlusions were performed at the end of expiration. $P_{0.1}$ and the maximal airway pressure value $\left(\mathrm{P}_{\max }\right)$ were calculated from the recordings using a recorder speed of $50 \mathrm{~mm} / \mathrm{s}$. A series of at least 10 occlusions were done, no more frequently than every $3 \mathrm{rd}$ breath. Occlusions that were not performed exactly at the end of expiration were excluded from analysis. $\dot{V}_{1}$ and $V_{T}$ were obtained by electronic integration of the respiratory flow signal. The timing components, i.e. inspiratory time $\left(T_{i}\right)$ and total cycle duration $\left(T_{t o t}\right)$, were measured using the flow signal from the unloaded breath immediately preceding the occluded inspiratory effort. The inspiratory "duty time" $\left(T_{i} / T_{t o t}\right)$ and mean inspiratory flow $\left(V_{T} / T_{i}\right)$ were computed from the above variables. To detect changes in respiratory mechanics due to prolonged hypoxemia, effective impedance $\left[\mathrm{P}_{0.1}\right]$ $\left.\left(V_{T} / T_{i}\right)\right]$ and elastance $\left(P_{\max } / V_{T}\right)$ were calculated. $P_{0.1}$ and $T_{i} / T_{\text {to }}$ are reported in absolute values and all volume data are normalized for body weight and expressed in $\mathrm{mL}$ per $\mathrm{kg}$.

Hypoxia tests. The lambs were subjected to mild $\left(0.14 \mathrm{FiO}_{2}\right)$ and severe $\left(0.10 \mathrm{FiO}_{2}\right)$ hypoxic challenges. After a 5 -min period of baseline ventilation when they were breathing $0.21 \mathrm{FiO}_{2}$, without disturbing the animals, $\mathrm{FiO}_{2}$ was abruptly changed to 0.14 and 0.10 , respectively, using a Bird High Flow Oxygen Blender (model 2900, Bird Corp.). The first minute thereafter was considered a mixing time in the circuits and was disregarded. $\dot{V}_{1}$ was continuously recorded during baseline and the following $15 \mathrm{~min}$ of hypoxia. The ventilatory response to hypoxia was expressed as percent change in $\dot{V}_{1}$ from baseline during each of the first $5 \mathrm{~min}$ and the 10 th and the 15 th min after onset of hypoxia. Arterial pH, $\mathrm{PaO}_{2}$, and $\mathrm{PaCO}_{2}$ were determined before and after 1, 5, 10, and 15 min of each hypoxia test.

Hyperoxia test. The transient pure oxygen inhalation test based on Dejours' original description (30) and the modification according to Purves and Biscoe (16) was used to determine the tonic CB activity. After 3-5 min of quiet breathing, the lamb was switched to $1.0 \mathrm{FiO}_{2}$ breathing for $1 \mathrm{~min}$. After a lag time of $10 \mathrm{~s}$, corresponding to the lung-peripheral circulation time, $\dot{V}_{1}$ was calculated during the next $10 \mathrm{~s}$ and the response to hyperoxia was expressed as percent change from baseline.

Tests were accepted as valid if the pretest baseline was stable 
and free of visible oscillations and not interrupted by sighs or coughs.

Statistics. Results are presented as mean values \pm SEM. Paired and unpaired $t$ tests were used for single-point comparison within one group or between groups, respectively. Values of $p<0.05$ were considered significant.

To assess whether prolonged hypoxemia merely delayed CB resetting or had an additional effect over this delay, we performed an overall analysis for $V_{1}$ (dependent variable), using multiple regression (the GLM procedure in PC-SAS version 6.04, SAS Institute, Inc., Cary, NC). This analysis compared results after adjusting for the duration of hypoxemia. For example, if hypoxemia merely delayed the $\mathrm{CB}$ resetting, then we would expect the results on d 16 for an animal with hypoxemia for $12 \mathrm{~d}$, i.e. $4 \mathrm{~d}$ after the end of hypoxemia, to be similar to those of a 5-d-old control animal. Thus, if the effect of hypoxemia is only to delay CB resetting, then the effect of treatment (hypoxemia or control) in this analysis should not be statistically significant. In addition to treatment, other independent variables in the model were the level of $\mathrm{O}_{2}$ in the hypoxia test $\left(0.10\right.$ or $\left.0.14 \mathrm{FiO}_{2}\right)$ treating $\mathrm{O}_{2}$ level as a categorical variable and age (for $\mathrm{C}$ lambs) or duration of life after initial hypoxemia (for $\mathrm{H}$ lambs). Duration was treated both as a continuous variable, implying that the change in an outcome variable was linear over time, and as a categoric variable using study number. We required that both analyses should give similar results before concluding that treatment did have an effect in addition to delaying $\mathrm{CB}$ reset to avoid dependence on the assumption of a linear effect over calendar time. In this model, we allowed for the fact that observations within a lamb are related. Because we were not interested in estimating results for specific lambs, we included lamb as a random effect within treatment in the regression model.

\section{RESULTS}

Change in body weight and behavior. There was no significant difference in body weight at birth (C lambs, $4.9 \pm 0.6 \mathrm{~kg} ; \mathrm{H}$ lambs, $5.1 \pm 0.4 \mathrm{~kg}$ ). The $\mathrm{H}$ lambs gained significantly less during the 12-d prolonged hypoxemia period compared with the $\mathrm{C}$ lambs $(1.3 \pm 0.2 \mathrm{~kg}$ versus $2.8 \pm 0.4 \mathrm{~kg}, p<0.05)$. The weight gain in the $\mathrm{H}$ lambs continued to be significantly less than that in the $C$ lambs through the 5 th study at $26 \mathrm{~d}$ of age. During the 12-d hypoxemia period, the $\mathrm{H}$ lambs were less active compared with the $C$ lambs.

Baseline $\dot{V}_{l}$. Recorded in $0.21 \mathrm{FiO}_{2}$ before the first hypoxia test, baseline $V_{1}$ decreased with increasing age and was similar in $\mathrm{C}$ and $\mathrm{H}$ lambs except at the age of $26 \mathrm{~d}$, when it was higher in the $\mathrm{H}$ lambs (Table 1).

Respiratory center output indices. $\mathrm{P}_{0.1}$ was significantly lower in the $\mathrm{H}$ lambs compared with the $\mathrm{C}$ lambs only at $16 \mathrm{~d}$ of age

Table 1. $\dot{V}_{I}\left(\mathrm{~mL} \cdot \mathrm{min}^{-1} \cdot \mathrm{kg}^{-1}\right)$ at baseline $\left(0.21 \mathrm{FiO}_{2}\right)$ before hypoxia tests*

Time after

\begin{tabular}{|c|c|c|c|}
\hline Age (d) & $\begin{array}{l}\text { Time after } \\
\text { prolonged hypoxemia } \\
\text { (d) }\end{array}$ & Control & Prolonged hypoxia \\
\hline 5 & & $512 \pm 56$ & $466 \pm 19$ \\
\hline 12 & & $453 \pm 36$ & $450 \pm 31$ \\
\hline 16 & 4 & $430 \pm 28$ & $376 \pm 31$ \\
\hline 19 & 7 & $381 \pm 32$ & $368 \pm 36$ \\
\hline 26 & 14 & $249 \pm 11$ & $349 \pm 9+$ \\
\hline 33 & 21 & $242 \pm 27$ & $296 \pm 17$ \\
\hline 40 & 28 & $295 \pm 20$ & $266 \pm 16$ \\
\hline 47 & 35 & $237 \pm 1$ & $268 \pm 36$ \\
\hline
\end{tabular}

* Values are mean \pm SEM.

† Statistically significant difference between the groups at $p<0.001$.
(Table 2). Mean inspiratory flow was not significantly different between the two groups. Inspiratory duty cycle decreased with age, especially in the $\mathrm{H}$ lambs, and was significantly diminished in these lambs at $40 \mathrm{~d}$ of age compared with the $C$ lambs.

Calculation of effective impedance and elastance of the respiratory system was performed to detect changes in respiratory mechanics (Table 2). Inspiratory impedance did not differ between the two groups, except during the first study, when the $\mathrm{H}$ lambs revealed a higher value than the $C$ lambs. Effective elastance was comparable in the two groups.

$\mathrm{PaO}_{2}$ and $\mathrm{PaCO}_{2}$. The average arterial blood gases in the lambs breathing different inspired oxygen concentrations are presented in Table 3. Baseline $\mathrm{PaO}_{2}$ in $0.21 \mathrm{FiO}_{2}$ was significantly lower in the $\mathrm{H}$ group at 12 and $33 \mathrm{~d}$ of age before the $0.10 \mathrm{FiO}_{2}$ test and at $16 \mathrm{~d}$ of age before the $0.14 \mathrm{FiO}_{2}$ test. The abrupt change from 0.21 to $0.10 \mathrm{FiO}_{2}$ or from 0.21 to $0.14 \mathrm{FiO}_{2}$ resulted in a fall in $\mathrm{PaO}_{2}$ as shown in Table 3. After $1 \mathrm{~min}$ of hypoxemia, $\mathrm{PaO}_{2}$ was not significantly different between groups except for a lower mean $\mathrm{PaO}_{2}$ in the $\mathrm{H}$ group at 16 and $33 \mathrm{~d}$ during $0.10 \mathrm{FiO}_{2}$ and at $16 \mathrm{~d}$ during $0.14 \mathrm{FiO}_{2}$. After $15 \mathrm{~min}$ of hypoxemia, $\mathrm{PaO}_{2}$ was similar in the two groups, except at $16 \mathrm{~d}$ during $0.10 \mathrm{FiO}_{2}$ and at 12 and $16 \mathrm{~d}$ during $0.14 \mathrm{FiO}_{2}$ when it was lower in the $\mathrm{H}$ group.

There was no difference in $\mathrm{PaCO}_{2}$ except for a lower baseline $\mathrm{PaCO}_{2}$ before the $0.14 \mathrm{FiO}_{2}$ test in the $\mathrm{H}$ group at $\mathrm{d} 5$ and a higher $\mathrm{PaCO}_{2}$ in the $\mathrm{H}$ group after $15 \mathrm{~min}$ at $\mathrm{d} 16$ (both 0.10 and $\left.0.14 \mathrm{FiO}_{2}\right)$ and $\mathrm{d} 19\left(0.10 \mathrm{FiO}_{2}\right)$ and after $1 \mathrm{~min}$ at $\mathrm{d} 47(0.14$ $\mathrm{FiO}_{2}$ ) as presented in Table 4.

Ventilatory response to acute hypoxic challenges. Both $\mathrm{C}$ and $\mathrm{H}$ lambs responded to $0.10 \mathrm{FiO}_{2}$ and $0.14 \mathrm{FiO}_{2}$ with an immediate increase in ventilation followed by a decline toward baseline. The stronger stimulus triggered the stronger response in both groups. The first phase of the ventilatory response was described by the peak response. It was defined as the single minute during which the change in $\dot{V}_{1}$ was the greatest and usually occurred during the $1 \mathrm{st}$ to $3 \mathrm{rd}$ min of hypoxemia. The peak ventilatory response to $0.10 \mathrm{FiO}_{2}$ in the $\mathrm{C}$ group was lowest at $5 \mathrm{~d}$ of age and increased thereafter (Fig. 1). The response at 5 d was significantly lower compared with the response at 12,16, 19,33 , and $40 \mathrm{~d}$. In the $\mathrm{H}$ group, the lowest peak ventilatory response to $0.10 \mathrm{FiO}_{2}$ occurred at $12 \mathrm{~d}$, at the end of prolonged hypoxemia. The responses at $5 \mathrm{~d}$ and at $16-19 \mathrm{~d}$ were of similar magnitude in this group and increased thereafter. Comparison between groups showed significantly lower ventilatory response to $0.10 \mathrm{FiO}_{2}$ at $12 \mathrm{~d}$ of age (last day of prolonged hypoxemia) and at $16,19,33$, and $47 \mathrm{~d}$ of age, which corresponds to 4,7 , 21 , and $35 \mathrm{~d}$ after completed prolonged hypoxemia. The peak ventilatory response to $0.14 \mathrm{FiO}_{2}$ was significantly less in the $\mathrm{H}$ group compared with the $C$ group when the lambs were 12,19 , and $26 \mathrm{~d}$ old, which corresponds with the last day of prolonged hypoxemia and until $14 \mathrm{~d}$ after completed hypoxemia.

The peak response to $0.10 \mathrm{FiO}_{2}$ at $5 \mathrm{~d}$ of age was seen at 2.6 $\pm 0.8 \mathrm{~min}$ after the onset of acute hypoxemia for the $\mathrm{C}$ lambs and at $2.0 \pm 0.4 \mathrm{~min}$ for the $\mathrm{H}$ lambs, but this difference was not statistically significant (Fig. 2). At $16 \mathrm{~d}$ of age, $4 \mathrm{~d}$ after prolonged hypoxemia, the peak response to $0.10 \mathrm{FiO}_{2}$ was significantly delayed in the $\mathrm{H}$ group compared with the $\mathrm{C}$ group $(3.3 \pm 0.4$ versus $1.0 \pm 0.0 \mathrm{~min})$ and the difference was statistically significant $(p<0.05)$. There were no significant differences in the time for peak response during the last five studies. The time for the peak response to $0.14 \mathrm{FiO}_{2}$ was similar in both groups.

The ventilatory response to 0.10 and $0.14 \mathrm{FiO}_{2}$ for the two groups at peak response, 5,10 , and $15 \mathrm{~min}$ of hypoxemia performed at $5,12,16$, and $47 \mathrm{~d}$ of age is presented in Figure 2. The response remained biphasic in both groups throughout the study period with a marked reduction in the response at 5,10 , and $15 \mathrm{~min}$ (second phase) compared with the peak response. The ventilatory response to $0.10 \mathrm{FiO}_{2}$ in the $\mathrm{H}$ group was considerably reduced during the first $5 \mathrm{~min}$ of the acute hypoxia 
Table 2. Respiratory data in $0.21 \mathrm{FiO}_{2}^{*}$

\begin{tabular}{|c|c|c|c|c|c|c|}
\hline & \multirow[b]{2}{*}{ Group } & \multicolumn{5}{|c|}{ Age } \\
\hline & & $5 \mathrm{~d}$ & $12 \mathrm{~d}$ & $16 \mathrm{~d}$ & $40 d$ & $47 d$ \\
\hline \multirow[t]{2}{*}{$\mathrm{P}_{0.1}\left(\mathrm{~cm} \mathrm{H}_{2} \mathrm{O}\right)$} & $\mathrm{C}$ & $3.4 \pm 0.2$ & $5.0 \pm 0.6$ & $4.5 \pm 0.4$ & $4.0 \pm 0.4$ & $3.2 \pm 0.1$ \\
\hline & $\mathrm{H}$ & $4.3 \pm 0.4$ & $4.3 \pm 0.5$ & $3.1 \pm 0.3 \dagger$ & $3.8 \pm 0.2$ & $4.4 \pm 0.4$ \\
\hline \multirow[t]{2}{*}{$\mathrm{V}_{\mathrm{T}} / \mathrm{T}_{\mathrm{i}}\left(\mathrm{mL} \cdot \mathrm{kg}^{-1} \cdot \mathrm{s}^{-1}\right)$} & $\mathrm{C}$ & $24.5 \pm 0.7$ & $26.9 \pm 2.5$ & $25.2 \pm 2.7$ & $17.6 \pm 0.9$ & $16.3 \pm 0.3$ \\
\hline & $\mathrm{H}$ & $24.7 \pm 4.5$ & $25.5 \pm 2.0$ & $21.1 \pm 2.5$ & $21.1 \pm 1.7$ & $18.7 \pm 2.2$ \\
\hline \multirow[t]{2}{*}{$T_{i} / T_{\text {tot }}\left(s \cdot s^{-1}\right)$} & $\mathrm{C}$ & $0.40 \pm 0.03$ & $0.38 \pm 0.02$ & $0.36 \pm 0.03$ & $0.36 \pm 0.03$ & $0.36 \pm 0.01$ \\
\hline & $\mathbf{H}$ & $0.40 \pm 0.03$ & $0.38 \pm 0.02$ & $0.38 \pm 0.02$ & $0.27 \pm 0.02 \dagger$ & $0.30 \pm 0.03$ \\
\hline \multirow{2}{*}{$\begin{array}{l}P_{0.1} /\left(V_{T} / T_{i}\right)\left(\mathrm{cm} \mathrm{H}_{2} \mathrm{O} \cdot \mathrm{mL}^{-1}\right. \\
\quad \mathrm{kg} \cdot \mathrm{s})\end{array}$} & $\mathrm{C}$ & $0.14 \pm 0.01$ & $0.19 \pm 0.02$ & $0.19 \pm 0.02$ & $0.23 \pm 0.03$ & $0.20 \pm 0.01$ \\
\hline & $\mathrm{H}$ & $0.18 \pm 0.01 \dagger$ & $0.17 \pm 0.01$ & $0.15 \pm 0.01$ & $0.18 \pm 0.01$ & $0.25 \pm 0.02$ \\
\hline \multirow[t]{2}{*}{$\mathrm{P}_{\max } / \mathrm{V}_{\mathrm{T}}\left(\mathrm{cm} \mathrm{H} \mathrm{H}_{2} \mathrm{O} / \mathrm{mL}\right)$} & $\mathrm{C}$ & $1.4 \pm 0.1$ & $1.7 \pm 0.1$ & $1.8 \pm 0.2$ & $2.4 \pm 0.2$ & $2.3 \pm 0.3$ \\
\hline & $\mathbf{H}$ & $1.8 \pm 0.1$ & $1.9 \pm 0.1$ & $1.7 \pm 0.1$ & $2.0 \pm 0.2$ & $2.5 \pm 0.2$ \\
\hline
\end{tabular}

* $P_{0.1}$, occlusion pressure; $V_{T} / T_{i}$, mean inspiratory flow; $T_{i} / T_{\text {tot }}$ inspiratory duty time; $P_{0.1} /\left(V_{T} / T_{i}\right)$, effective impedance; $P_{\text {max }} / V_{T}$ effective elastance. Values are mean \pm SEM.

+ Different from control at $p<0.05$.

Table 3. Effect of acute hypoxia on $\mathrm{PaO}_{2}(\mathrm{kPa})^{*}$

\begin{tabular}{|c|c|c|c|c|c|c|c|c|c|}
\hline \multirow{2}{*}{$\begin{array}{l}\text { Age } \\
\text { (d) }\end{array}$} & \multirow{2}{*}{$\begin{array}{c}\text { Time after } \\
\text { H (d) }\end{array}$} & \multirow[b]{2}{*}{ Group } & \multirow[b]{2}{*}{$n$} & \multicolumn{3}{|c|}{ Response to $0.10 \mathrm{FiO}_{2}$} & \multicolumn{3}{|c|}{ Response to $0.14 \mathrm{FiO}_{2}$} \\
\hline & & & & $0 \mathrm{~min}$ & $1 \mathrm{~min}$ & $15 \mathrm{~min}$ & $0 \mathrm{~min}$ & $1 \mathrm{~min}$ & $15 \mathrm{~min}$ \\
\hline \multirow[t]{2}{*}{5} & & $\mathrm{C}$ & 5 & $13.2 \pm 0.6$ & $5.0 \pm 0.2$ & $3.9 \pm 0.2$ & $12.7 \pm 0.5$ & $6.6 \pm 0.3$ & $5.7 \pm 0.5$ \\
\hline & & $\mathrm{H}$ & 5 & $11.4 \pm 0.8$ & $4.5 \pm 0.3$ & $3.2 \pm 0.1$ & $11.4 \pm 0.4$ & $6.5 \pm 0.4$ & $5.1 \pm 0.1$ \\
\hline \multirow[t]{2}{*}{12} & & $\mathrm{C}$ & 5 & $13.6 \pm 0.6$ & $5.1 \pm 0.1$ & $3.6 \pm 0.1$ & $11.9 \pm 0.5$ & $7.7 \pm 0.6$ & $6.2 \pm 0.5$ \\
\hline & & $\mathrm{H}$ & 7 & $11.4 \pm 0.4 \dagger$ & $4.8 \pm 0.2$ & $3.1 \pm 0.2$ & $11.1 \pm 0.4$ & $6.2 \pm 0.4$ & $4.7 \pm 0.4 \dagger$ \\
\hline \multirow[t]{2}{*}{16} & 4 & $\mathrm{C}$ & 4 & $13.0 \pm 0.4$ & $5.3 \pm 0.2$ & $4.2 \pm 0.1$ & $12.7 \pm 0.3$ & $7.0 \pm 0.3$ & $6.0 \pm 0.3$ \\
\hline & & $\mathrm{H}$ & 6 & $11.5 \pm 0.5$ & $4.4 \pm 0.1 \dagger$ & $3.1 \pm 0.1 \dagger$ & $10.9 \pm 0.5 \dagger$ & $5.9 \pm 0.2 \dagger$ & $4.7 \pm 0.2 \dagger$ \\
\hline \multirow[t]{2}{*}{19} & 7 & $\mathrm{C}$ & 4 & $12.7 \pm 0.1$ & $5.1 \pm 0.1$ & $4.0 \pm 0.3$ & $12.3 \pm 0.5$ & $7.2 \pm 0.2$ & $5.7 \pm 0.3$ \\
\hline & & $\mathbf{H}$ & 6 & $11.9 \pm 0.3$ & $5.1 \pm 0.1$ & $3.5 \pm 0.1$ & $11.5 \pm 0.4$ & $6.8 \pm 0.1$ & $5.4 \pm 0.1$ \\
\hline \multirow[t]{2}{*}{26} & 14 & $\mathrm{C}$ & 4 & $12.4 \pm 0.6$ & $5.4 \pm 0.2$ & $4.1 \pm 0.3$ & $12.7 \pm 0.5$ & $7.3 \pm 0.2$ & $5.9 \pm 0.6$ \\
\hline & & $\mathrm{H}$ & 4 & $12.6 \pm 0.2$ & $4.9 \pm 0.2$ & $3.5 \pm 0.1$ & $11.9 \pm 0.1$ & $6.7 \pm 0.3$ & $5.3 \pm 0.4$ \\
\hline \multirow[t]{2}{*}{33} & 21 & C & 4 & $13.0 \pm 0.3$ & $5.6 \pm 0.2$ & $4.0 \pm 0.2$ & $12.0 \pm 0.3$ & $6.8 \pm 0.2$ & $5.4 \pm 0.3$ \\
\hline & & $\mathbf{H}$ & 5 & $11.4 \pm 0.5 \dagger$ & $4.5 \pm 0.2 \dagger$ & $3.5 \pm 0.2$ & $11.6 \pm 0.3$ & $6.6 \pm 0.3$ & $5.2 \pm 0.3$ \\
\hline \multirow[t]{2}{*}{40} & 28 & $\mathrm{C}$ & 3 & $12.8 \pm 0.7$ & $5.3 \pm 0.2$ & $4.3 \pm 0.5$ & $11.9 \pm 0.2$ & $7.0 \pm 0.2$ & $5.8 \pm 0.4$ \\
\hline & & $\mathrm{H}$ & 4 & $11.5 \pm 0.2$ & $5.3 \pm 0.3$ & $3.9 \pm 0.2$ & $11.5 \pm 0.3$ & $6.7 \pm 0.2$ & $5.4 \pm 0.3$ \\
\hline \multirow[t]{2}{*}{47} & 35 & $\mathrm{C}$ & 2 & $12.2 \pm 0.1$ & $5.3 \pm 0.0$ & $3.8 \pm 0.3$ & $12.3 \pm 0.3$ & $7.2 \pm 0.2$ & $5.7 \pm 0.5$ \\
\hline & & $\mathrm{H}$ & 5 & $11.9 \pm 0.6$ & $5.2 \pm 0.2$ & $3.9 \pm 0.2$ & $11.9 \pm 0.4$ & $7.3 \pm 0.3$ & $5.7 \pm 0.3$ \\
\hline
\end{tabular}

*Values are mean \pm SEM.

$\dagger$ Different from control at $p<0.05$.

Table 4. Effect of acute hypoxia on $\mathrm{PaCO}_{2}(\mathrm{kPa})^{*}$

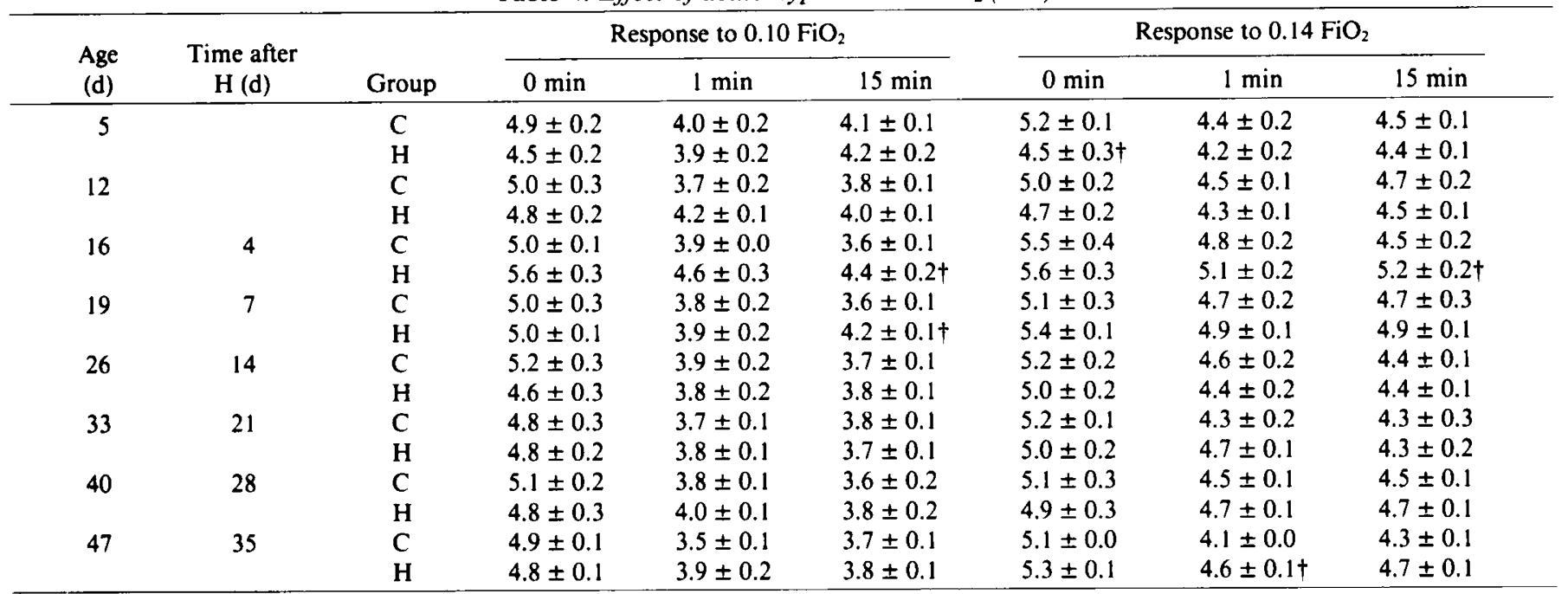

* Values are mean \pm SEM.

+ Different from control at $p<0.05$. 


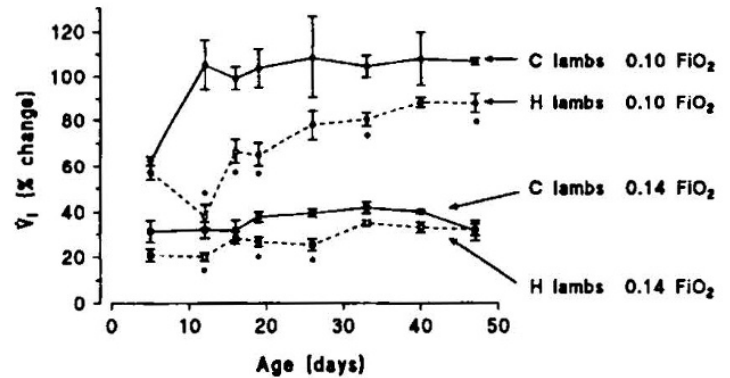

Fig. 1. Peak ventilatory response to hypoxia after a change in $\mathrm{FiO}_{2}$ from 0.21 to 0.14 or from 0.21 to 0.10 expressed as percent increase in $\dot{\mathrm{V}}_{1}$ in seven lambs that experienced prolonged hypoxemia $\left(0.10 \mathrm{FiO}_{2}\right)$ during the first 12 postnatal days and five $C$ lambs (mean \pm SEM). *, Statistically significant difference between the groups at $p<0.05$.

test at $12 \mathrm{~d}$ of age (the last day of prolonged hypoxemia). The ventilatory response at 10 and $15 \mathrm{~min}$ was not significantly different between the two groups during any of the study sessions. The ventilatory response never dropped below the baseline level in either group.

A similar, although less pronounced, response pattern was seen when $0.14 \mathrm{FiO}_{2}$ was used as an acute hypoxia test (Fig. 2).

Changes in $V_{T}$ and $R R$ during acute hypoxemia. To further analyze the ventilatory response to acute hypoxemia, the changes in $\mathrm{V}_{\mathrm{T}}$ and $\mathrm{RR}$ were calculated during the $0.10 \mathrm{FiO}_{2}$ test at $12 \mathrm{~d}$, when the effect of prolonged hypoxemia was most pronounced. A significant decrease from the peak $V_{T}$ value was observed at 10 and $15 \mathrm{~min}$ in the $C$ lambs, when the average $V_{T}$ was below baseline (Fig. 3). There was no significant change in $V_{T}$ from the peak value in the $\mathrm{H}$ lambs. There was no statistically significant difference in $V_{T}$ response between the groups. A significant decrease from the peak RR value was observed at 5,10 , and 15 min in the $C$ lambs, but no significant change in $R R$ from the peak value was observed in the $H$ lambs. The $R R$ response was significantly lower in the $\mathrm{H}$ lambs compared with the $\mathrm{C}$ lambs at peak time and at $5 \mathrm{~min}$.

Timed-shifted result analysis. A multiple regression model was used to assess whether prolonged hypoxemia merely delayed $\mathrm{CB}$ resetting with a time corresponding to the duration of hypoxemia or whether it had an additional effect on this delay.

There was a highly significant difference in baseline $\dot{V}_{1}(p<$ $0.05)$, percent change in ventilation at $1 \mathrm{~min}(p<0.001)$, and percent change at peak ventilation $(p<0.01)$. There was no consistent evidence for differences between groups in percent change in ventilation at 5,10 , or $15 \mathrm{~min}$.

Ventilatory response to hyperoxia. Ventilatory response to an abrupt change from $0.21 \mathrm{FiO}_{2}$ to $1.0 \mathrm{FiO}_{2}$ was characterized by an immediate fall in ventilation in all animals (Fig. 4). The response to hyperoxia increased gradually during the first $19 \mathrm{~d}$ after birth in the $C$ group. In contrast, the ventilatory response to hyperoxia remained essentially unchanged between 5 and 12 $\mathrm{d}$ of age in the $\mathrm{H}$ group. The response to hyperoxia was significantly lower in the $\mathrm{H}$ group compared with the $\mathrm{C}$ group on the last day of hypoxemia, when the lambs were $12 \mathrm{~d}$ old. The response to hyperoxia was similar in the two groups at $16 \mathrm{~d}$ of age ( $4 \mathrm{~d}$ after completed hypoxemia) and thereafter.

\section{DISCUSSION}

This study shows that the ventilatory response to acute hypoxia can be markedly attenuated if newborn lambs are exposed to a hypoxic environment for a prolonged time after birth. This effect was extended and did not merely represent an offset corresponding to the time spent in hypoxia. In contrast, the ventilatory response to hyperoxia was only attenuated at the end of the hypoxemia period and was similar in the two groups thereafter.
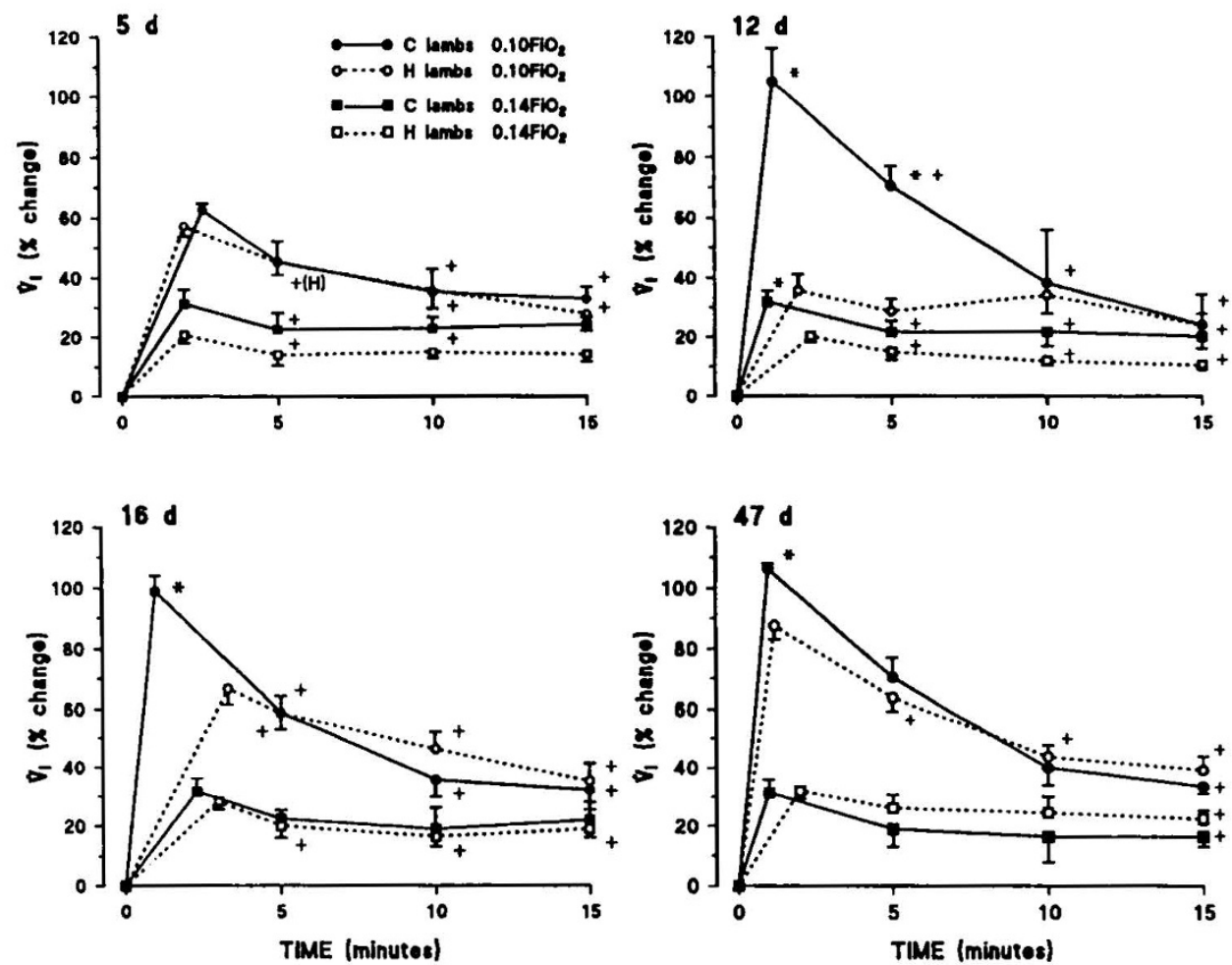

Fig. 2. Ventilatory response to a change in $\mathrm{FiO}_{2}$ from 0.21 to 0.14 and from 0.21 to 0.10 expressed as percent increase in $\dot{\mathrm{V}}_{1}$ at the time of peak response, 5,10 , and $15 \mathrm{~min}$ of hypoxemia in seven lambs that experienced prolonged hypoxemia $\left(0.10 \mathrm{FiO}_{2}\right)$ during the first 12 postnatal days and five $C$ lambs. Studies shown were performed at $5 \mathrm{~d}$ of age; $12 \mathrm{~d}$ of age, last day of prolonged hypoxemia; $16 \mathrm{~d}$ of age, $4 \mathrm{~d}$ after completed prolonged hypoxemia; and $47 \mathrm{~d}$ of age, $35 \mathrm{~d}$ after completed prolonged hypoxemia (mean $\pm \mathrm{SEM}$ ). ${ }^{*}$, Statistically significant differences between the groups at $p<0.05$. + , Statistically significant difference compared with peak value within the group at $p<0.05$. 

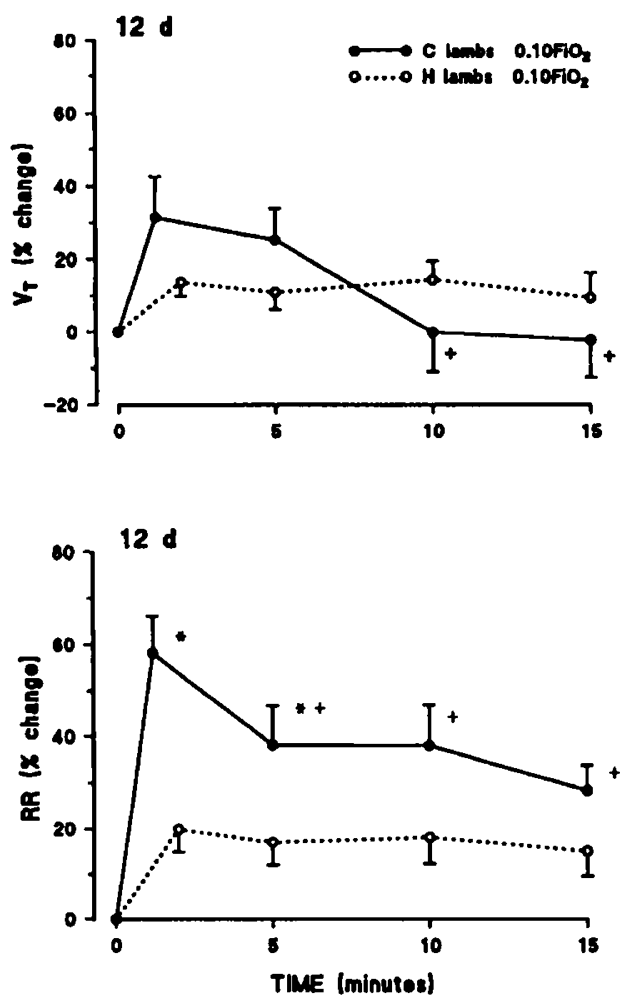

Fig. 3. $\mathrm{V}_{\mathrm{T}}$ and $\mathrm{RR}$ response to a change in $\mathrm{FiO}_{2}$ from 0.21 to 0.10 expressed as percent change from baseline in seven lambs that experienced prolonged hypoxemia $\left(0.10 \mathrm{FiO}_{2}\right)$ during the first 12 postnatal days and five $C$ lambs (mean $\pm \mathrm{SEM}$ ). *, Statistically significant difference between the groups at $p<0.05$. + , Statistically significant difference compared with peak value within the group at $p<0.05$.

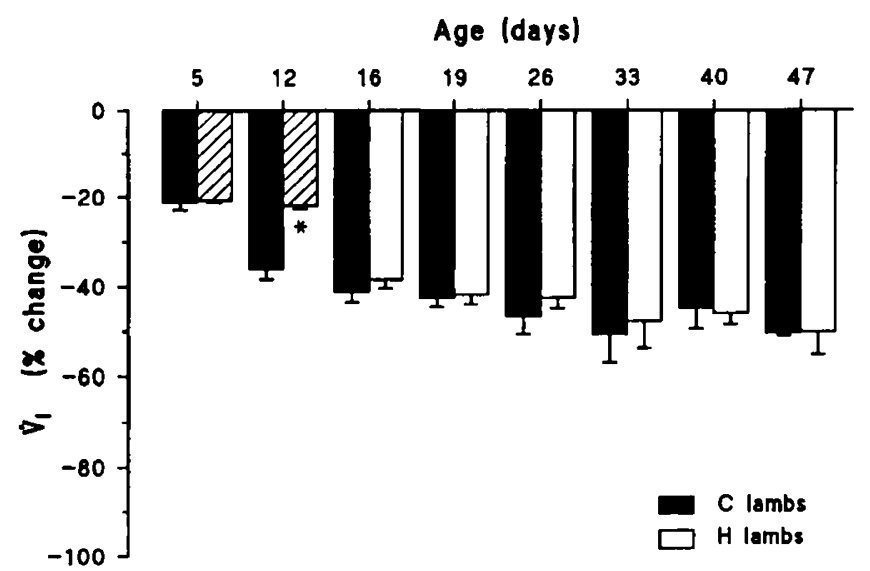

Fig. 4. Ventilatory response to hyperoxia expressed as percent decrease in $\dot{V}_{1}$ after a change from 0.21 to $1.0 \mathrm{FiO}_{2}$ in seven lambs that experienced prolonged hypoxemia $\left(0.10 \mathrm{FiO}_{2}\right)$ during the first 12 postnatal days and five $C$ lambs (mean \pm SEM). *, Statistically significant difference between the groups at $p<0.05$.

The peak ventilatory response to acute hypoxia was both delayed and depressed after prolonged hypoxemia. The magnitude of the immediate ventilatory response to acute hypoxia is considered to be a reflection of the chemoreceptor strength (3, 31). The response of the $C B$ receptors to acute hypoxemia undergoes a period of resetting during the first $1-2$ postnatal weeks $(2,4,17,20)$. In this study, there was a marked increase between $\mathrm{d} 5$ and $\mathrm{d} 12$ in the peak ventilatory response to 0.10 $\mathrm{FiO}_{2}$, whereas the response to $0.14 \mathrm{FiO}_{2}$ was already well developed at $\mathrm{d} 5$. The difference in developmental change in the response to mild or severe acute hypoxia may indicate that the arterial chemoreceptors undergo a progressive resetting to different levels of $\mathrm{PaO}_{2}$.

A delayed development of a mature ventilatory response beyond the age when normoxic animals have developed an adult response has previously been shown after prolonged hypoxemia in newborn rats (27) and kittens (21). Eden and Hanson (27) proposed that ventilation during acute hypoxemia in the neonate can be discussed in terms of two opposing components: 1 ) the peripheral arterial chemoreceptors that stimulate ventilation ( 3 , 31 ) and 2) a CNS component that inhibits ventilation, e.g. persistence of the suprapontine mechanism, which suppresses ventilation during hypoxemia in the fetus $(12,32)$. Based on whole carotid sinus nerve recordings, they concluded that the suppressed ventilatory response to acute hypoxia in the chronically hypoxemic rats was caused by a shift in the balance to the central inhibition. However, this group later demonstrated that the single- or few-fiber carotid chemoreceptor response to acute hypoxemia was markedly attenuated in chronically hypoxemic kittens kept hypoxemic for 2 wk compared with age-matched controls (33). Further support for an abnormal function or delayed maturation of the peripheral chemoreceptor sensitivity to acute hypoxemia after chronic hypoxemia comes from studies by Hanson et al. (21), who used a two-breath alteration of $\mathrm{FIO}_{2}$ method in chronically hypoxemic kittens. In adult cats, however, prolonged hypoxemia decreases the peripheral chemoreceptor responsiveness to a decrease in $\mathrm{PaO}_{2}$ and also attenuates the CNS translation of chemoreceptor input (26).

As previously shown by Bureau et al. (31), the ventilatory response to acute hypoxia consisted of an increase in both $V_{T}$ and RR. In the control lambs, the increase in RR was larger and more sustained compared with the increase in $V_{T}$. After $12 \mathrm{~d}$ of prolonged hypoxemia, the increase in $R R$ in response to 0.10 $\mathrm{FiO}_{2}$ was significantly attenuated during the first phase of the response compared with that in the $C$ lambs. However, the increases in $V_{T}$ and $R R$ in the $H$ lambs were more sustained during the test compared with those in the $C$ lambs.

Newborn infants and animals characteristically have a biphasic ventilatory response to acute hypoxia (31) that is characterized by transient hyperventilation followed by ventilatory depression. Such a biphasic response is related to postnatal maturity and is replaced by a more sustained ventilatory response in adults (31). The reason for the roll-off from the peak value has not been definitely delineated but is generally believed to be caused by a central mechanism (34-36) rather than a failure of the peripheral chemoreceptors to sustain afferent input (37).

In our study, the roll-off from the peak ( 5 to $15 \mathrm{~min}$ ) was more pronounced during stimulation with $0.10 \mathrm{FiO}_{2}$ than with 0.14 $\mathrm{FiO}_{2}$. There was a significant difference between the groups only at the age of $12 \mathrm{~d}$, at the end of prolonged hypoxemia. At that time, the reduced second phase was probably mostly related to low afferent input from the peripheral chemoreceptors rather than from a central influence, inasmuch as both the peak response to hypoxemia and the response to hyperoxemia were blunted. Already $4 \mathrm{~d}$ later, the magnitude of the second phase was similar in the two groups, indicating that prolonged hypoxemia mostly influences the first phase of the ventilatory response which is mainly considered to be a reflection of peripheral chemoreceptor function.

We did not find marked changes in the neuromuscular drive during baseline conditions, which would indicate that the reduced response to acute hypoxia is most likely dependent on altered peripheral chemoreceptor function and/or the central mechanism that integrates their afferent signal rather than a generalized depressive effect on the respiratory center. Changes in metabolism induced by prolonged hypoxemia that could be reflected in diminished activity of the neuronal networks responsible for integrated functions such as breathing should also be considered. However, we did not find a significant difference between the groups in baseline $\dot{\mathrm{V}}_{1}$ or $\mathrm{PaCO}_{2}$. Baseline oxygen consumption was only significantly different at $5 \mathrm{~d}$ of age, when 
it was lower in the $\mathrm{H}$ group, yet the ventilatory response to acute hypoxia was not different (data not shown).

Respiratory output during the acute hypoxia tests was expressed as $\dot{V}_{l}$, which may be affected by factors other than respiratory drive, e.g. changes in respiratory mechanics. The $\mathrm{H}$ lambs showed decreased gain of body weight during the prolonged hypoxemia period. Lung growth and muscle development may have been affected as well, which could have modified the linkage between neural and mechanical output. It has been suggested that an increase in effective impedance and elastance reflects a decrease in dynamic compliance and/or an increase in airway resistance (38-40). Although we can not exclude the possibility that changes in pulmonary mechanics were present in the $\mathrm{H}$ lambs, absence of significant differences in baseline effective impedance and elastance during the studies performed at an age of 12 to $47 \mathrm{~d}$ may indicate that marked changes in pulmonary mechanics were not a major cause of the attenuated ventilatory response to acute hypoxia.

The upper airway was bypassed in these studies, because a tracheostomy tube was used to monitor ventilation. In tracheostomized lambs during hypoxia, Johnson et al. (41) have shown that respiratory reflexes may influence patency of the larynx and may alter the pattern of breathing. However, they also showed that applying positive airway pressure-as performed in this study-restored a normal response to acute hypoxia.

The differences found in the ventilatory response to acute hypoxia cannot be explained by differences in $\mathrm{PaCO}_{2}$, because in general $\mathrm{PaCO}_{2}$ was not significantly different between the groups. While breathing room air, lambs exposed to prolonged hypoxemia had significantly lower $\mathrm{PaO}_{2}$ at baseline compared with controls, which probably was not related to a decreased function of the peripheral chemoreceptors, inasmuch as ventilation was unaffected, but which might have been a result of ventilationperfusion mismatching secondary to marked pulmonary hypertension (data not shown).

Our study and that of Mortola et al. (42) showed that prolonged hypoxemia after birth has a long-lasting effect on the response to acute hypoxemia, but in contrast to them we did not observe persistent hyperventilation after return to room air. The probable cause of desensitization is that the low level of $\mathrm{PaO}_{2}$ from birth alters the development of the peripheral chemoreceptors and/or the neural centers responding to their impulses. There may be a critical maturational time after birth when the sensitivity of the peripheral chemoreceptors is determined and when hypoxemia permanently alters CB sensitivity. The study of Sorensen and Severinghaus (43) showed that the weak response to acute hypoxia in natives of high altitude remains even if they move to sea level. These authors also reported that in children who have been hypoxemic for many years, as a result of tetralogy of Fallot, response to acute hypoxia is blunted even after surgical correction (44).

Arterial chemoreceptor tonic input during normoxic breathing can be evaluated by the short hyperoxia test (29), and it has been widely used to assess peripheral chemoreceptor function in the newborn period $(17,45)$. The basic principal is that the decrease in ventilation, evoked by a withdrawal of the stimulus from the arterial chemoreceptors, can be regarded as an index of the tonic influence of the receptors. The immediate depression of ventilation during hyperoxemia is, therefore proportional to the chemoreceptor influence before the oxygen inhalation. In agreement with Bureau et al. (17), we found a significant increase with age in the response to pure oxygen in the control lambs that corresponded to an increasing response to acute hypoxia.

The response to hyperoxia in the $\mathrm{H}$ lambs remained small during the $12 \mathrm{~d}$ of prolonged hypoxemia but had already normalized within $4 \mathrm{~d}$ of normoxic breathing, which is in contrast to the prolonged depression of the immediate ventilatory response to acute hypoxia. This divergence of effects further raises the possibility that central inhibitory effects modified the response to acute hypoxia. The other possible explanation of our results could be that different mechanisms are examined when oxygen sensitivity of the peripheral chemoreceptors is tested with acute hypoxia or acute hyperoxia. The hyperoxia test examines the tonic drive from the receptor, whereas the acute hypoxemia test determines the gain of the peripheral chemoreceptors.

Studies by Hertzberg et al. (45) have shown that the emergence of chemoreceptor sensitivity to hyperoxia in newborn rats was preceded by a prompt drop in dopamine turnover rate, suggesting that a high dopamine release keeps the chemoreceptor sensitivity low in the immediate newborn period. This concept was supported by the finding that rats born and reared in hypoxia showed an attenuated chemoreflex response that coincided with a maintained turnover of CB dopamine (46). During the postnatal period, the CB may undergo a gradual release from a dopaminemediated inhibition governed by the prevailing arterial oxygenation, which modulates the sensitivity of the arterial chemoreceptor. This process may be inhibited by prolonged hypoxemia.

In conclusion, this study has shown that postnatal maturation of the ventilatory response to acute hypoxia or hyperoxia can be delayed by prolonged postnatal hypoxemia. As indicated by the response to hyperoxia, the tonic activity of the peripheral chemoreceptors is rapidly normalized after return to normoxia. The early ventilatory response to acute hypoxia is affected for an extended time, whereas the second phase is comparable to that in controls shortly after discontinued prolonged hypoxemia. These results indicate that prolonged hypoxemia in newborn lambs causes a delay in the postnatal reset of the sensitivity of the peripheral chemoreceptors and/or alters the development of the neural centers responding to their impulses. This study illustrates the importance of an adequate postnatal $\mathrm{PaO}_{2}$ for the development of the ventilatory response to acute hypoxia. We speculate that a reduced ability to generate a forceful hyperventilatory response to acute hypoxia may be clinically relevant in infants who have experienced prolonged or intermittent hypoxemia after birth.

Acknowledgments. The authors thank Dr. Mildred T. Stahlman for her support and advice; Stanley Poole, MS, Patricia Minton, RN, and Rao Gaddipati, MS, for their skilled technical assistance; and Donna Staed for typing the manuscript.

\section{REFERENCES}

1. Lahiri S, Gelfand R, Mokashi A, Nishino T 1978 Significance of peripheral chemoreceptor response and adaptation in the regulation of breathing. Adv Exp Med Biol 99:343-353

2. Belenky DA, Standaert TA, Woodrum DE 1979 Maturation of hypoxic ventilatory response of the newborn lamb. J Appl Physiol 47:927-930

3. Bureau MA, Lamarche J, Foulon P. Dalle D 1985 The ventilatory response to hypoxemia in the newborn lamb after carotid body denervation. Respir Physiol 60:109-119

4. Grogaard JB, Kreuger E, Lindstrom D, Sundell H 1986 Effects of carotid body maturation and terbutaline on the laryngeal chemoreflex in newborn lambs. Pediatr Res 20:724-729

5. Purves MJ 1974 Onset of respiration at birth. Arch Dis Child 49:333-343

6. Jansen AH, Chernick V 1991 Fetal breathing and development of control breathing. J Appl Physiol 70:1431-1446

7. Blanco CE, Dawes GS, Hanson MA, McCooke HB 1984 The response to hypoxemia of arterial chemoreceptors in fetal sheep and newborn lambs. J Physiol 351:26-37

8. Blanco CE, Hanson MA, McCooke HB 1988 Effects on carotid chemoreceptor resetting of pulmonary ventilation in the fetal lamb in utero. J Dev Physiol 10:167-174

9. Murai DT, Lee CH, Wallen LD, Kitterman JA 1985 Denervation of peripheral chemoreceptors decreases breathing movements in fetal sheep. J Appl Physiol 59:575-579

10. Rurak DW, Cooper C 1984 The effect of relative hypoxemia on the pattern of breathing movements in fetal lambs. Respir Physiol 55:23-37

11. Boddy K, Dawes GS, Fisher R, Pinter S, Robinson JS 1974 Foetal respiratory movements, electrocortical and cardiovascular responses to hypoxaemia and hypercapnia in sheep. J Physiol (Lond) 243:599-618

12. Edelman NH, Melton JE, Neubauer JA 1991 Central adaptation to hypoxemia In: Lahiri S, Cherniack NS, Fitzgerald RS (eds) Response and Adaptation to Hypoxia. Oxford University Press, New York, pp 235-243

13. Gluckman PD, Johnston BM 1987 Lesions in the upper lateral pons abolish the hypoxic depression of breathing in unanesthetized fetal lambs in utero. $\mathrm{J}$ Physiol (Lond) 382:373-383

14. Johnston BM, Walker DW 1986 Respiratory responses to changes in oxygen 
and carbon dioxide in the perinatal period. In: Johnston BM, Gluckman PD (eds) Respiratory Control and Lung Development in the Fetus and Newborn. Perinatology Press, Ithaca, NY, pp 279-310

15. Baier RJ, Hasan SU, Cates DB, Hooper D, Nowaczyk B, Rigatto H 1990 Effects of various concentrations of $\mathrm{O}_{2}$ and umbilical cord occlusion on fetal breathing and behavior. J Appl Physiol 68:1597-1604

16. Purves MJ, Biscoe TJ 1966 Development of chemoreceptor activity. Br Med Bull 22:56-60

17. Bureau MA, Begin $R 1982$ Postnatal maturation of the respiratory response to $\mathrm{O}_{2}$ in awake newborn lambs. J Appl Physiol 52:428-433

18. Reynolds SRM, Mackie JD 1961 Development of chemoreceptor response sensitivity: studies in fetuses, lambs, and ewes. Am J Physiol 201:239-250

19. Bureau MA, Lamarche J, Foulon P, Dalle D 1985 Postnatal maturation of respiration in intact and carotid body chemodenervated lambs. J Appl Physiol 59:869-874

20. Eden GJ, Hanson MA 1987 Maturation of the respiratory response to acute hypoxia in the newborn rat. J Physiol (Lond) 392:1-9

21. Hanson MA, Kumar P, Williams BA 1989 The effect of chronic hypoxia upon the development of respiratory chemoreflexes in the newborn kitten. J Physiol (Lond) 411:563-574

22. Hunt CE 1992 Sudden infant death syndrome. In: Beckerman RC, Brouillette RT, Hunt CE (eds) Respiratory Control Disorders in Infants and Children. Williams \& Wilkins, Baltimore, pp 190-211

23. Henderson-Smart DJ, Cohen GL 1988 Chemical control of breathing in early life. In: Schwartz PJ, Southall DP, Valdes-Dapena M (eds) The Sudden Infant Death Syndrome. Cardiac and Respiratory Mechanism and Interactions. NY Academy of Sciences, New York, pp 276-289

24. Hunt CE, McCulloch K, Brouillette RT 1981 Diminished hypoxic ventilatory responses in near-miss sudden infant death syndrome. J Appl Physiol 50:1313-1317

25. Barnard P, Andronikou S, Pokorski M. Smatresk N, Mokashi A. Lahiri S 1987 Time-dependent effect of hypoxia on carotid body chemosensory function. J Appl Physiol 63:685-691

26. Tatsumi K, Pickett CK, Weil JV 1991 Attenuated carotid body hypoxic sensitivity after prolonged hypoxic exposure. J Appl Physiol 70:748-755

27. Eden GJ. Hanson MA 1987 Effects of chronic hypoxia from birth on the ventilatory response to acute hypoxia in the newborn rat. J Physiol (Lond) 392:11-19

28. Hanson MA, Kumar P, McCooke HB 1986 Post-natal resetting of carotid chemoreceptor sensitivity in the lamb. J Physiol 382:57(abstr)

29. Whitelaw WA, Derenne JP, Milic-Emili 1975 Occlusion pressure as a measure of respiratory center output in conscious man. Respir Physiol 23:181-199

30. Dejours $P 1962$ Chemoreflexes in breathing. Physiol Rev 42:335-358

31. Bureau MA, Zinman R, Foulon $P$, Begin R 1984 Diphasic ventilatory response to hypoxia in newborn lambs. J Appl Physiol 56:84-90

32. Dawes GS, Gardner WN, Johnston BM, Walker DW 1983 Breathing in fetal lambs: the effect of brain stem section. J Physiol (Lond) 335:535-554

33. Hanson MA, Eden GJ, Nijhuis JG, Moore PJ 1989 Peripheral chemoreceptors and other $\mathrm{O}_{2}$ sensors in the fetus and newborn. In: Lahiri S, Forster RE. Davies RO, Pack AI (eds) Chemoreceptors and Reflexes in Breathing. Oxford University Press, New York, pp 113-120

34. Blanco CE, Hanson MA, Johnson P, Rigatto $H 1984$ Breathing pattern of kittens during hypoxia. J Appl Physiol 56:12-17

35. Martin-Body RL, Johnston BM 1988 Central origin of the hypoxic depression of breathing in the newborn. Respir Physiol 71:25-32

36. Lawson EE, Long WA 1983 Central origin of biphasic breathing pattern during hypoxia in newborns. J Appl Physiol 55:483-485

37. Carroll JL. Bureau MA 1987 Decline in peripheral chemoreceptor excitatory stimulation during acute hypoxia in the lamb. J Appl Physiol 63:795-802

38. Lynne-Davies P, Couture J. Pengelly LD, Milic-Emili J 1971 Immediate ventilatory response to added inspiratory elastic loads in cats. J Appl Physiol 30:512-516

39. Wyszogrodski I, Thach BT, Milic-Emili J 1978 Maturation of respiratory control in unanesthetized newborn rabbits. J Appl Physiol 44:304-310

40. LaFramboise WA, Standaert TA, Woodrum DE, Guthrie RD 1981 Occlusion pressures during the ventilatory response to hypoxemia in the newborn monkey. J Appl Physiol 51:1169-1174

41. Johnson P. Fewell JE Fedorko LM Wollner JC 1983 The vagal control of breathing in postnatal life: implications for sleep related respiratory failure. In: Tildon JT, Roeder LM. Steinschneider A (eds) Sudden Infant Death Syndrome. Academic Press, New York, pp 467-490

42. Mortola JP, Morgan CA, Virgonu N 1986 Respiratory adaptation to chronic hypoxia in newborn rats. J Appl Physiol 61:1329-1336

43. Sorensen SC. Severinghaus JW 1968 Irreversible respiratory insensitivity to acute hypoxia in man born at high altitude. J Appl Physiol 25:217-220

44. Sorensen SC, Severinghaus JW 1968 Respiratory insensitivity to acute hypoxia persisting after correction of tetralogy of Fallot. J Appl Physiol 25:221-223

45. Hertzberg T, Hellstrom S, Lagercrantz H, Pequignot JM 1990 Development of the arterial chemoreflex and turnover of carotid body catecholamines in the newborn rat. J Appl Physiol 425:211-225

46. Hertzberg T, Hellstrom S, Holgert H, Lagercrantz H, Pequignot JM 1992 Ventilatory response to hyperoxia in newborn rats born in hypoxia: possible relationship to carotid body dopamine. J Physiol (Lond) 456:645-654 